Bright x-ray sources from laser irradiation of foams with high concentration of $\mathrm{Ti}$

F. Perez, J. Patterson, M. May, J. Colvin, M. Biener, A. Wittstock, S. Kucheyev, S. Charnvanichborikarn, J. Satcher, S. Gammon, J. Poco, S. Fujioka, Z. Zhang, K. Ishihara, N. Tanaka, T. Ikenouchi, H. Nishimura, K. Fournier

November 20, 2013

Physics of Plasmas 
This document was prepared as an account of work sponsored by an agency of the United States government. Neither the United States government nor Lawrence Livermore National Security, LLC, nor any of their employees makes any warranty, expressed or implied, or assumes any legal liability or responsibility for the accuracy, completeness, or usefulness of any information, apparatus, product, or process disclosed, or represents that its use would not infringe privately owned rights. Reference herein to any specific commercial product, process, or service by trade name, trademark, manufacturer, or otherwise does not necessarily constitute or imply its endorsement, recommendation, or favoring by the United States government or Lawrence Livermore National Security, LLC. The views and opinions of authors expressed herein do not necessarily state or reflect those of the United States government or Lawrence Livermore National Security, LLC, and shall not be used for advertising or product endorsement purposes. 


\title{
Bright $x$-ray sources from laser irradiation of foams with high concentration of $\mathrm{Ti}$
}

\author{
F. Pérez, ${ }^{1,}$ a) J. R. Patterson, ${ }^{1}$ M. May, ${ }^{1}$ J. D. Colvin, ${ }^{1}$ M. M. Biener, ${ }^{1}$ A. Wittstock, ${ }^{1}$ S. O. Kucheyev, ${ }^{1}$ \\ S. Charnvanichborikarn, ${ }^{1}$ J. H. Satcher, Jr., ${ }^{1}$ S. A. Gammon, ${ }^{1}$ J. F. Poco, ${ }^{1}$ S. Fujioka, ${ }^{2}$ Z. Zhang, ${ }^{2}$ K. Ishihara, ${ }^{2}$ \\ N. Tanaka, ${ }^{2}$ T. Ikenouchi, ${ }^{2}$ H. Nishimura, ${ }^{2}$ and K. B. Fournier ${ }^{1}$ \\ 1) Lawrence Livermore National Laboratory, 7000 East Ave., Livermore CA 94550 USA \\ ${ }^{2)}$ Institute of Laser Engineering, Osaka Univ., 2-6 Yamada-Oka, Suita, Osaka 565-0871 Japan
}

Low-density foams irradiated by a 20 kilojoule laser at the Omega laser facility (NY, USA) are shown to convert more than $5 \%$ of the laser energy into 4.6 to $6.0 \mathrm{keV}$ x rays. This record efficiency with foam targets is due to novel fabrication techniques based on atomic-layer-deposition of $\mathrm{Ti}$ atoms on an aerogel scaffold. A Ti concentration of 33 atomic $\%$ was obtained in a foam with a total density of $5 \mathrm{mg} / \mathrm{cm}^{3}$. The dynamics of the ionization front through these foams were investigated at the 1 kilojoule laser of the Gekko XII facility (Japan). Hydrodynamic simulations can reproduce the average electron temperature but fail to predict accurately the heat front velocity in the foam. This discrepancy is shown to be unrelated to the possible water adsorbed in the foam but could be attributed to effects of the foam micro-structure.

\section{INTRODUCTION}

Achieving intense multi-keV x-ray sources is of great importance for several applications such as radiography for inertial fusion plasmas ${ }^{1,2}$ and high-energy-density studies with x-ray-driven ablation ${ }^{3}$. Many of these applications require few-nanosecond-long sources that are as bright as possible. Laser-created plasmas have the advantage of providing flexible, bright, and short x-ray pulses, from the femtosecond to nanosecond scale. Laserheated targets typically contain mid-Z elements such as $\mathrm{Ti}, \mathrm{Fe}, \mathrm{V}, \mathrm{Ge}$, or $\mathrm{Kr}$, their K-shell line emission providing 4 to $15 \mathrm{keV} \times$ rays. For instance, metal foils ${ }^{4}$, gasfilled targets $^{5,6}$, metal-doped aerogels ${ }^{7-9}$, pre-exploded foils $^{10}$, metal oxide nano-fibers ${ }^{11}$, and aerogels attached to foils ${ }^{12}$, can achieve 1 to $10 \%$ laser-to-x-ray conversion efficiencies (CE) in a limited energy range.

Metal-doped foams can reach high CEs when their density is low enough $\left(<10 \mathrm{mg} / \mathrm{cm}^{3}\right)$ so that the laser gets absorbed deeper in the target thus volumetrically heating the plasma. Various types of such foams can, in principle, be achieved by tailoring the material composition, density, and pore size. Previous work ${ }^{7,8}$ has shown that foams containing various dopants ( $\mathrm{Ti}, \mathrm{Fe}, \mathrm{Ge}$, etc.) could be volumetrically heated when the density is in the range of 5 to $10 \mathrm{mg} / \mathrm{cm}^{3}$. This very low density, homogeneous over a $\mathrm{mm}^{3}$, is a challenge for target fabrication, and the chemistry for only a few of these foams has been worked out. Maximizing the fraction of metal dopant at these ultra-low densities is an additional challenge.

In this Article, we present laser-driven x-ray sources using highly-concentrated foams: 20 to 33 atomic $\%$ of $\mathrm{Ti}$ with a total density $\lesssim 5 \mathrm{mg} / \mathrm{cm}^{3}$. These novel targets are shown to be highly efficient, reaching CEs up to 17 times higher than previous aerogels with a Ti concentration of $\sim 4$ at. \%. Absolute x-ray yield measurements

\footnotetext{
a) Electronic mail: perez75@llnl.gov
}

show CEs of $5 \%$, which can possibly be doubled in future experiments. This performance is found specifically in the $\mathrm{x}$-ray emission of interest, i.e., around the He- $\alpha$ transition of $\mathrm{Ti}$ at $4.7 \mathrm{keV}$. To our knowledge, this is the highest conversion efficiency to date from foam targets. The higher Ti concentration mostly explains the gain in $\mathrm{x}$-ray emission. An additional important reason is that the lower quantity of the other atoms (here, Si and O) means they emit less lower-energy $\mathrm{x}$ rays that contribute to cooling the plasma.

We also present measurements of the foam heating dynamics, which we compare to radiation-hydrodynamics simulations. The current state-of-the-art modeling shows some discrepancies with the experimental data, already reported recently in similar conditions ${ }^{12}$. Resolving these discrepancies is a necessary step for future target design, and we consider here limitations of the numerical models, the role of possible contamination of the foams with water molecules, and the influence of the foam structure (as opposed to a uniform medium).

Two experiments were performed in two different laser facilities. The first one was carried out with the Omega laser ${ }^{13}$ at the Laboratory for Laser Energetics (Rochester, NY). We present here absolute x-ray yield measurements and 2D x-ray images of both low (4 at. \%) and high-concentration (20 at. \%) aerogels. The second experiment, conducted at the Gekko XII facility ${ }^{14}$ of the Institute of Laser Engineering (Osaka, Japan), provided relative yields only, but its near-1D geometry provided insightful measurements of heating dynamics. Additionally, it featured novel nano-tubular foams with an even higher Ti concentration (33 at. \%).

In section II, we present briefly the target fabrication process. Sections III and IV detail the experimental results obtained at the Omega and Gekko XII facilities, respectively. Numerical simulations are described and discussed with respect to the experimental measurements in section V. Finally, we conclude with observations on the performance and physics of the novel foams in section VI. 


\begin{tabular}{cccc} 
Type & Composition & Ti concentration & Density \\
\hline \hline $\mathrm{A}$ & $\mathrm{SiO}_{2}+\mathrm{TiO}_{2}$ & 4 at. $\%$ & $3.7 \mathrm{mg} / \mathrm{cm}^{3}$ \\
$\mathrm{~B}$ & $\mathrm{SiO}_{2}+\mathrm{TiO}_{2}$ & 20 at. $\%$ & $4 \mathrm{mg} / \mathrm{cm}^{3}$ \\
$\mathrm{C}$ & $\mathrm{TiO}_{2}$ & 33 at. $\%$ & 5 to $18 \mathrm{mg} / \mathrm{cm}^{3}$
\end{tabular}

Table I. Types of foams studied here.

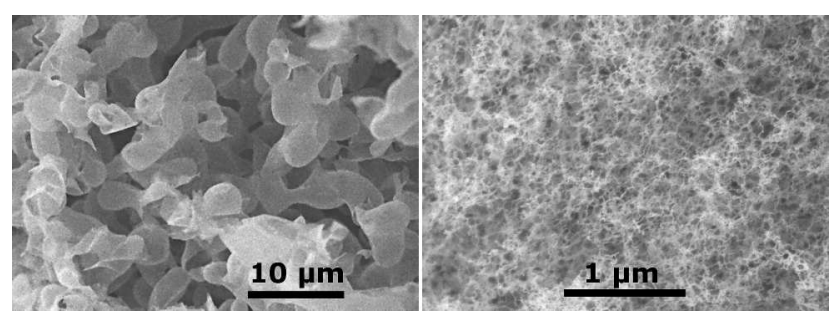

Figure 1. Scanning electron microscope images of foam types $\mathrm{C}\left(5 \mathrm{mg} / \mathrm{cm}^{3}\right.$, left-hand side) and B (right-hand side).

\section{HIGH-TI-CONCENTRATION FOAMS}

Three types of foams, which we refer to as A, B, and $\mathrm{C}$, were tested on the Omega and Gekko XII laser facilities. Their characteristics are summarized in Table I and scanning electron microscope images for types B and C are given in Fig. 1. All foams were cast or held inside $2 \mathrm{~mm}$-long polyimide tubes. For the Omega experiment, these tubes had a $2 \mathrm{~mm}$ inner diameter and a $50 \mu \mathrm{m}$-thick wall (see section III). For the Gekko XII experiment, they had a $1 \mathrm{~mm}$ inner diameter and a $25 \mu \mathrm{m}$-thick wall (see section IV).

Type A was used in previous studies ${ }^{7,15,16}$ and is considered here as a reference case: the Ti concentration is relatively low and the density is $3.7 \mathrm{mg} / \mathrm{cm}^{3}$. The general procedure for preparing ultra-low-density aerogels involves the formation of a partially polymerized condensed silica (CS) pre-polymer produced from monomeric tetramethoxysilane (TMOS) as previously described ${ }^{17,18}$. To fabricate a $\mathrm{TiO}_{2}$-doped silica aerogel, a mixed-composition CS pre-polymer is formed by reacting fixed ratios of TMOS and titanium (IV) ethoxide monomers in an acetone solvent. Using this mixture, ultra-low-density wet gels are formed by reactions that complete the polymerization with additional solvent to dictate the final density. The wet gels are subsequently dried to aerogels by removing the solvent above its critical temperature and pressure using the rapid supercritical extraction process ${ }^{19}$.

The aerogel type $\mathrm{B}$ is of similar composition as type A: $\mathrm{SiO}_{2}$ and $\mathrm{TiO}_{2}$. Its fabrication starts with a $1 \mathrm{mg} / \mathrm{cm}^{3}$ $\mathrm{SiO}_{2}$ aerogel scaffold, derived as above, which is coated with $\mathrm{TiO}_{2}$ using the $\mathrm{TiCl}_{4} / \mathrm{H}_{2} \mathrm{O}$ atomic layer deposition (ALD) process (see Ref. 20), with a growth rate of $\sim$ $0.07 \mathrm{~nm}$ per cycle at $110^{\circ} \mathrm{C}$. The resulting aerogel has a high Ti concentration of 20 at. \% for a very low monolith density of $4 \mathrm{mg} / \mathrm{cm}^{3}$.

The third type $(\mathrm{C})$ is a pure $\mathrm{TiO}_{2}$ foam thus reaching an even higher Ti concentration of 33 at. \%. Its fabrication starts with a nano-porous gold (np-Au) template with a porosity of $\sim 70 \%$, prepared by selective dissolution of machined $\mathrm{Ag}_{0.7} \mathrm{Au}_{0.3}$ alloy cylinders ( $2 \mathrm{~mm}$-long) in concentrated nitric acid ${ }^{21}$. The feature size of the template is adjusted to $350 \mathrm{~nm}, 1 \mu \mathrm{m}$, and $3 \mu \mathrm{m}$ by annealing at 500,700 , and $900{ }^{\circ} \mathrm{C}$, respectively ${ }^{22}$. The annealed $\mathrm{np}-\mathrm{Au}$ template is inserted into a polyimide tube of the same size and coated with several nm-thick $\mathrm{TiO}_{2} \mathrm{ALD}$ films using either 30 (for 500 and $700{ }^{\circ} \mathrm{C}$ samples) or 50 (for $900{ }^{\circ} \mathrm{C}$ samples) cycles of the $\mathrm{TiCl}_{4} / \mathrm{H}_{2} \mathrm{O}$ ALD process. Finally, the np-Au template is removed using a standard $\mathrm{KI} / \mathrm{I}_{2}$ wet etch process ${ }^{23}$ and supercritical drying of the resulting nano-tubular foam. These pure $\mathrm{TiO}_{2}$ foams have densities of 5,8 or $18 \mathrm{mg} / \mathrm{cm}^{3}$.

The elemental composition of all target types was determined by a combination of Rutherford backscattering spectrometry (RBS) with $2 \mathrm{MeV}^{4} \mathrm{He}^{+}$ions (at a scattering angle of $164^{\circ}$ ) and elastic recoil detection analysis $(\text { ERDA })^{24}$ with $3 \mathrm{MeV}^{4} \mathrm{He}^{+}$ions. All ion beam experiments were performed at room temperature in vacuum conditions comparable to those of the laser shots. The analysis of RBS and ERDA spectra was done with the RUMP code ${ }^{25}$ with stopping powers and Rutherford scattering cross sections for $\mathrm{O}, \mathrm{Si}$ and $\mathrm{Ti}$ and a cross-section for the ${ }^{1} \mathrm{H}\left({ }^{4} \mathrm{He},{ }^{1} \mathrm{H}\right){ }^{4} \mathrm{He}$ reaction from Ref. 26. During the ERDA experiment, the sample normal direction was tilted by $70^{\circ}$ with respect to the incident He beam, and $\mathrm{H}$ atoms recoiled at $150^{\circ}$ were collected with a surface barrier detector covered with a $10-\mu \mathrm{m}$-thick carbon foil that filtered out the forward-scattered He ions. A representative spectrum is given in Fig. 2. The edge at $\sim 1 \mathrm{MeV}$ corresponds to $\mathrm{H}$ atoms recoiled from the sample surface. Spectral counts at lower energies are representative of $\mathrm{H}$ atoms recoiled from deeper regions in the sample as both incident $\mathrm{He}$ ions and recoiled $\mathrm{H}$ atoms lose energy while propagating through the material. As illustrated in Fig. 2, a simulation of ERDA spectra with the RUMP code reveals a uniform $7-10$ at. \% of $\mathrm{H}$ content for foams of type A and B. Other details regarding material synthesis and characterization will be the subject of separate publications.

\section{EXPERIMENT ON OMEGA}

Forty beams of the Omega laser were used to irradiate the foams, 20 on each face of the cylinder, as illustrated in Fig. 3. Each beam delivered $\sim 500 \mathrm{~J}$ to the target in a $1 \mathrm{~ns}$ square pulse, for a total of $20 \mathrm{~kJ}$ on target at a wavelength of $351 \mathrm{~nm}$. Their focusing was chosen for an approximately uniform $10^{15} \mathrm{~W} / \mathrm{cm}^{2}$ irradiance over a $1 \mathrm{~mm}$-diameter area. They were timed to reach the target faces in coincidence. Details regarding the Omega laser, the target chamber, and each diagnostic instrument can be found in the National Laser User Facility User's Guide $^{27}$. 


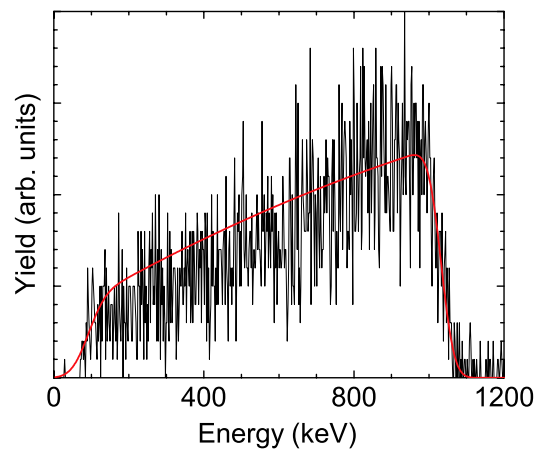

Figure 2. (Color online) Representative ERDA spectrum from a type-B foam. The yield is proportional to the number of recoiled hydrogen atoms reaching the detector in each spectral channel. The smooth line is a RUMP code simulation result corresponding to a depth-uniform hydrogen content of $\sim 7$ at. $\%$.

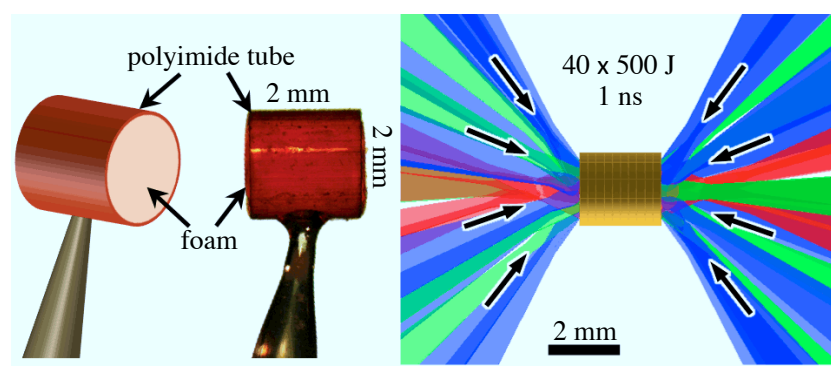

Figure 3. (Color online) Left: schematic and photograph of a target used at the Omega laser facility. Right: corresponding laser irradiation geometry.

Only target types A and B were shot at the Omega facility.

\section{A. Absolute x-ray yields}

The time-resolved x-ray-diode-based DANTE instrument $^{28}$ was employed to measure the $\mathrm{x}$-ray power from the target in 11 energy channels spanning a wide range $(60 \mathrm{eV}-6 \mathrm{keV})$. The detectors are vacuum x-ray diodes with $\mathrm{Al}, \mathrm{Ni}$, or $\mathrm{Cr}$ cathodes and filtration depending on the energy range to be detected. Time-resolved signals from the diodes are acquired using high-speed $(5 \mathrm{GHz})$ digitizers. DANTE is absolutely calibrated in a synchrotron facility, and absolute x-ray yields can be determined from the waveforms of each channel. These calibrated time-resolved x-ray powers (in several energy ranges) are the key diagnostic for measuring the laser-to-X-ray conversion efficiency.

Type-A targets were consistently measured to provide $13 \pm 3 \mathrm{~J} / \mathrm{sr}$ of $\mathrm{x}$ rays in the K-shell range (between 4.6 and $6.0 \mathrm{keV}$ ), i.e., a $\mathrm{CE}$ of $0.8 \pm 0.2 \%$. In the full range of the DANTE instrument, an x-ray yield from 730 to $800 \mathrm{~J} / \mathrm{sr}$ was measured, corresponding to a $\mathrm{CE}$ of $48 \pm$

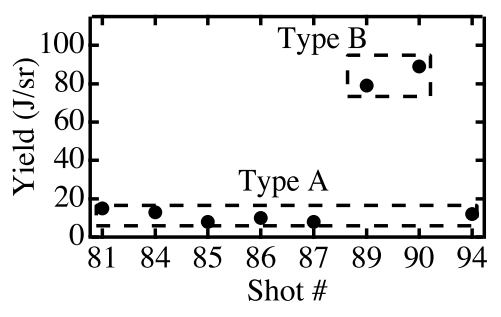

Figure 4. K-shell x-ray emission as measured on DANTE.
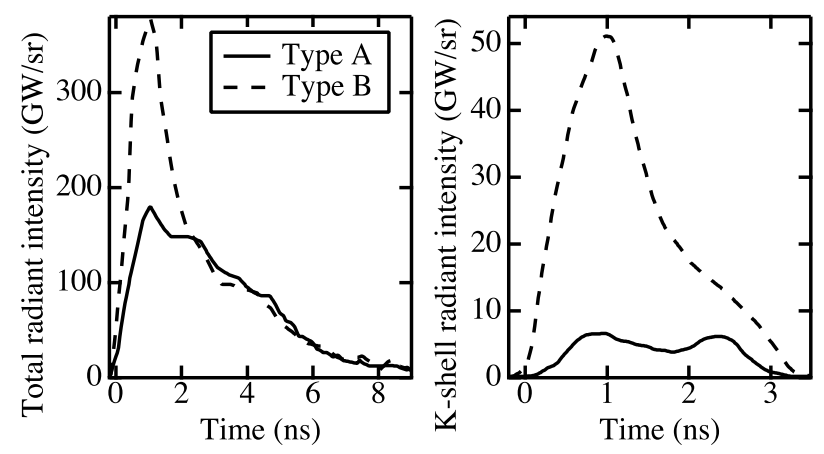

Figure 5. Total (left) and K-shell (right) x-ray emission vs time, as measured on DANTE, for target types A and B.

$2 \%$. The type-B targets provided a significantly higher yield: $84 \pm 8 \mathrm{~J} / \mathrm{sr}$ in the K-shell range, or a CE of $5.3 \pm$ $0.5 \%$, and $970 \pm 70 \mathrm{~J} / \mathrm{sr}$ in the full range, or a CE of $61 \pm$ $5 \%$. The reproducibility of these results is illustrated in Fig. 4 summarizing eight shots taken at Omega. The $5 \%$ conversion efficiency into the $\mathrm{K}$-shell range is comparable with other types of targets such as foil-lined hohlraums ${ }^{29}$. To the authors' knowledge, it is the highest CE measured from a foam material.

This 7( \pm 2 )-fold yield increase in CE from type-B foams is mainly due to their composition: they contain approximately 5 times more Ti atoms per unit volume than aerogels of type A. It is also expected that the lower amount of low-Z atoms results in less parasitic radiative cooling, thus a higher temperature and a higher x-ray yield, but this effect was not quantified.

The time-dependence of the yield from two targets is plotted in Fig. 5. The total emitted power for typeB target is twice that of type-A targets, at early times, when the laser is on. Later, when the laser pulse is over, they almost exactly match, showing that both targets are thermally expanding at the rate determined by the injected energy into the system. K-shell yields are however very different between different types of targets. The K-shell flux from a type B target shows an increase by a factor of $\sim 7$ compared to that of type $\mathrm{A}$.

In addition, we notice two bumps in the K-shell flux from the type-A target. This corresponds to a re-compression of the plasma due to the polyimide tube being heated and imploding towards the cylinder axis, as has been noted previously $^{8,9}$. 


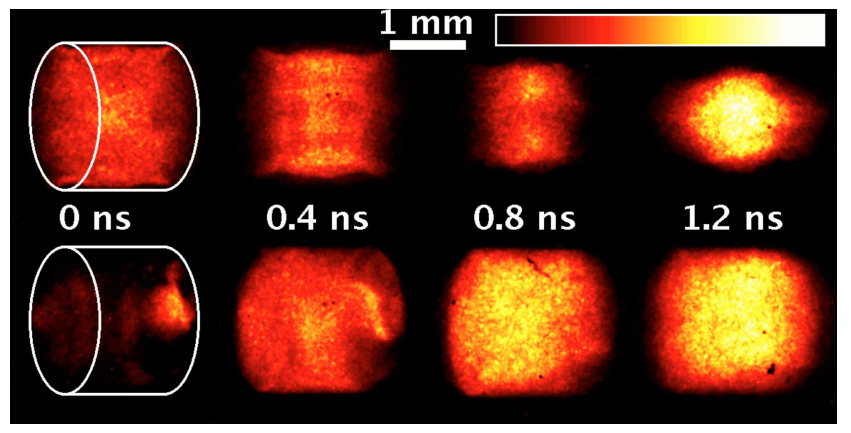

Figure 6. (Color online) Images of the Ti K-shell emission at four different times $( \pm 0.2 \mathrm{~ns})$. The top and bottom rows correspond to targets of types $\mathrm{A}$ and $\mathrm{B}$, respectively.

\section{B. Gated x-ray images}

An x-ray framing camera (XRFC) monitored the target heating dynamics and homogeneity ${ }^{30}$. It imaged the $\mathrm{X}-$ ray emission through an array of twelve pinholes onto a gated micro-channel-plate detector. The XRFC has a near side-on view of the target and captures heat front propagation and plasma expansion along the target axis. It is configured to produce three sequential exposures (each lasting $50 \mathrm{ps}$ ), beginning at $t=0 \mathrm{~ns}, 0.4 \mathrm{~ns}, 0.8 \mathrm{~ns}$, and $1.2 \mathrm{~ns}$ (twelve exposures total, $\pm 0.1 \mathrm{~ns}$ ). The camera is filtered with a $254 \mu \mathrm{m}$-thick Be foil to eliminate soft $\mathrm{x}$ rays and a $16 \mu \mathrm{m}$-thick Ti foil to attenuate harder $\mathrm{x}$ rays.

Typical images from the XRFC are shown in Fig. 6 for targets of types A and B. The first row shows that type-A targets emit uniformly at early times, then progressively emit only from the center of the cylinder. It is attributed to the polyimide tube being ablated by $\mathrm{x}$ rays from the foam plasma or laser energy that reaches the tube wall, either of which causes the plasma then to be imploded. This is consistent with the compression mentioned in the DANTE measurements above. The x-ray emission can be sustained longer from this re-compression.

The second row in Fig. 6 indicates a different behavior of the type-B targets. The heating homogenizes rapidly and a complete volumetric emission is observed. The recompression effect is much weaker for this type of target.

\section{EXPERIMENT ON GEKKO XII}

Nine beams of the Gekko XII laser were bundled in one gaussian spot of radius $\sim 100 \mu \mathrm{m}$ irradiating only one face of the cylindrical targets, as shown in Fig. 7. The gaussian temporal shape had a $1.3 \mathrm{~ns}$ full width at half maximum for a maximum intensity of $\sim 2 \cdot 10^{15} \mathrm{~W} / \mathrm{cm}^{2}$ and a total energy of $\sim 1 \mathrm{~kJ}$.

Foam types A, B, and C were used at the Gekko XII facility. Type $\mathrm{C}$ was available with three different densities:

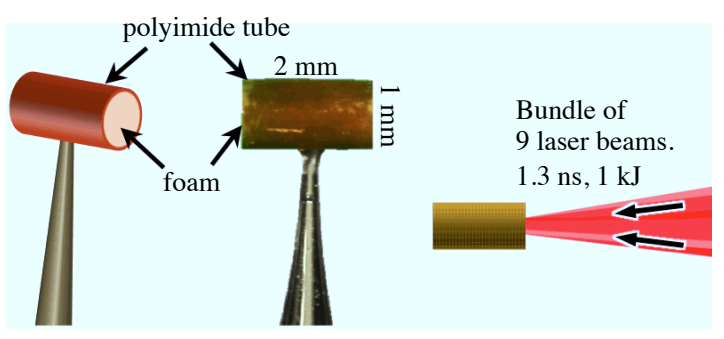

Figure 7. (Color online) Left: schematic and photograph of a target used at the Gekko XII laser facility. Right: corresponding laser irradiation geometry.

5,8 and $18 \mathrm{mg} / \mathrm{cm}^{3}$.

\section{A. Time-integrated spectra}

An x-ray spectrometer was used at the Gekko XII laser to determine the spectral content of the Ti K-shell emission. It consisted of a flat rubidium acid phthalate crystal (interatomic distance $2 d=26.121 \AA$ ) reflecting $5 \mathrm{keV} \mathrm{x}$ rays with a Bragg angle of $\sim 5.4^{\circ}$ and a spectral range from 4.6 to $6.3 \mathrm{keV}$. A slit placed between the target and the crystal provided $\mathrm{a} \sim 200 \mu \mathrm{m}$ spatial resolution in the direction of the cylinder axis. The space-resolved spectra were collected on an x-ray CCD camera.

Fig. 8 presents three spectra (solid lines) obtained with foams of types A, B and C. Several emission lines are visible, among which the He- $\alpha$ and Ly- $\alpha$ groups are most interesting as they are sensitive to the electron temperature. At first sight, one can observe that the He- $\alpha$ group provides most $(>80 \%$ ) of the $\mathrm{x}$ rays and that this amount is much greater in targets types B and C, than in type A. In fact, as previously measured at the Omega facility (see section III A), the total x-ray emission in the $4.6-6.0 \mathrm{keV}$ range is 7 times larger using foams of type $\mathrm{B}$ compared to type $\mathrm{A}$. The performance of foams of type $\mathrm{C}$ appears even higher: they yielded 13 to 17 times more $\mathrm{x}$ rays than type-A aerogels. This corresponds to a $\mathrm{CE}$ from type $\mathrm{C}$ approximately twice that from type-B aerogels. Unfortunately, no absolute measurement was available on this facility, but we can extrapolate this factor 2 to the performance obtained with the Omega results from section III A: as the type-B aerogels were measured to have a $\mathrm{CE}$ of $5 \%$, we can expect the $\mathrm{CE}$ to reach $10 \%$ with these type-C targets, which would be close to the highest $\mathrm{CE}$ obtained with laser-driven sources in this energy range ${ }^{31}$. Note that pure $\mathrm{TiO}_{2}$ targets fabricated with the density $27 \mathrm{mg} / \mathrm{cm}^{3}$ using a different technique achieved a CE of $3.7 \%$ in the same energy range ${ }^{11}$.

In order to obtain quantitative information on the temperature of the plasma that emitted most of the Kshell $\mathrm{x}$ rays, we ran atomic simulations using the code $\mathrm{SCRAM}^{32}$, which produces x-ray spectra given a uniform plasma self-consistently accounting for absorption of the 


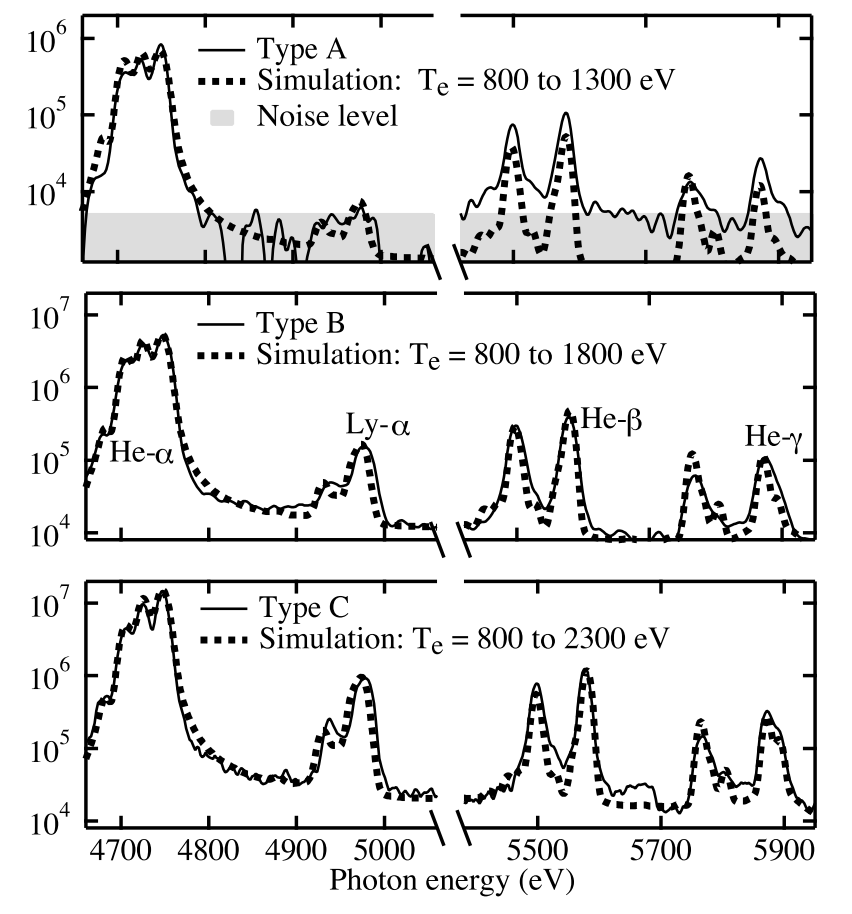

Figure 8. Time- and space-integrated x-ray spectra (arbitrary units) measured from three foam types at the Gekko XII facility. Solid lines are experimental measurements. Dotted lines are best matches from atomic simulations using the code SCRAM, each obtained with a distribution of electron temperatures which range is indicated in the legends.

emitted light. After verifying that the simulated spectra did not significantly depend on the plasma density, we simulated several cases corresponding to temperatures between 0.5 and $3.0 \mathrm{keV}$. Using a distribution of equallyweighted temperatures, best matches to the experimental spectra are plotted in Fig. 8. The most relevant criterion for defining a good fit to the data is the ratio between Ly- $\alpha$ and He- $\alpha$ lines. For type-A aerogels, temperatures ranging from 0.8 to $1.3 \mathrm{keV}$ reproduces well the experimental spectrum. For type-B targets, the range from 0.8 to $1.8 \mathrm{keV}$ provides the excellent agreement shown on Fig. 8. For foams of type $\mathrm{C}$, the best range depends on the foam density.

Overall, the three types of foams exhibit different temperatures, according to the x-ray spectrometer results. All cases presented a significant portion of the spectrum originating from $\mathrm{a} \sim 1 \mathrm{keV}$ plasma. The targets with higher Ti concentration (B and $\mathrm{C}$ ) always show a hotter component, between 1.5 and $2.3 \mathrm{keV}$. Using the spectrometer spatial resolution, we determined that this hot plasma is located in the first half of the target, typically in the first 0.5 or $1 \mathrm{~mm}$.

The maximum value of the temperature range used in SCRAM simulations, corresponding to the best fits with experimental data, is plotted $v$ foam density in Fig. 9 (left). The temperature increases rapidly with density until $10 \mathrm{mg} / \mathrm{cm}^{3}$ and increases slowly thereafter.
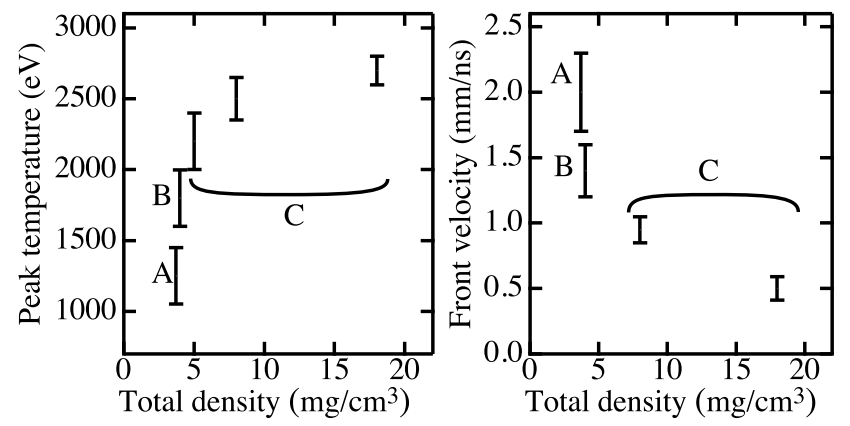

Figure 9. Left: peak plasma temperature as inferred from $\mathrm{x}-$ ray spectra $v s$ foam density (section IV A). Right: heat front velocity as inferred from the streak camera vs foam density (section IV B).
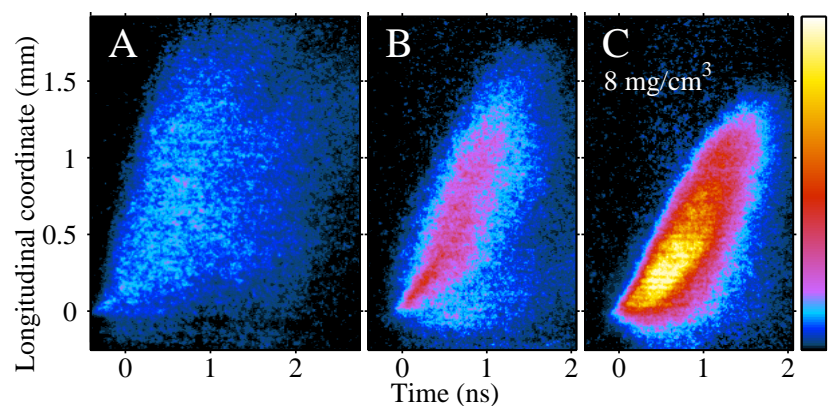

Figure 10. (Color online) Streak camera data from three targets of different types (A, B and $\mathrm{C}$ ). The targets extend between 0 and $2 \mathrm{~mm}$. The lasers interact with the targets at 0 $\mathrm{mm}$.

\section{B. Time-resolved $x$-ray imaging}

A streak camera was used to determine the plasma heating dynamics. A $15 \times 50 \mu \mathrm{m}^{2}$ slit casts an image of the target from which the central region (along the cylinder axis) was selected on a CsI cathode with a $<50 \mu \mathrm{m}$ resolution. Streaking this one-dimensional image then provided a temporal resolution $<0.1 \mathrm{~ns}$.

Typical data from the streak camera are presented in Fig. 10. The targets emit $x$ rays starting from the irradiated surface, then progressively emit from regions deeper inside the target.

A good parameter for further studying the heating dynamics is the heat front velocity. We choose to define this front as the location of the half-maximum of the $\mathrm{x}$ ray signal on the photocathode. From the data (Fig. 10) we measured the position of this front at different times and inferred its velocity. We found this front velocity to be fairly constant during most of the laser-target interaction. The results are plotted on the right-hand side in Fig. 9 as a function of the foam density. The velocity decreases rapidly until $10 \mathrm{mg} / \mathrm{cm}^{3}$ and then more slowly for higher densities.

Previous work has shown similar results using type-A 
targets: Tanabe et al. ${ }^{16}$ obtained a lower velocity (1 to $1.5 \mathrm{~mm} / \mathrm{ns}$ at the laser peak power) with a laser intensity four times lower; Constantin et al. ${ }^{15}$ obtained a rapidly changing velocity from 3 to $0.3 \mathrm{~mm} / \mathrm{ns}$ in a nanosecond, but in a very different laser illumination geometry; Primout et al. ${ }^{12}$ obtained velocities ranging from 1 to $2 \mathrm{~mm} / \mathrm{ns}$ in $\mathrm{SiO}_{2}$ aerogels for laser conditions similar to ours.

Our findings reveal that the heating dynamics differ in the several targets used. The increase of temperature with increasing density could be caused by deposition of the same energy in a smaller heated volume at the front of the target, which results from the decrease of the heat front velocity.

\section{SIMULATIONS}

Two-dimensional radiation-hydrodynamics simulations have been carried out with the LASNEX $\operatorname{code}^{33}$ in a cylindrical geometry. The equations of motion are solved in a Lagrangian formulation, with the equation of state determined from the non-local thermal equilibrium (nonLTE) rate equations. The ray-tracing laser propagation includes inverse bremsstrahlung absorption on free electrons, whose density is determined from the ionization levels calculated in the incorporated super-configuration non-LTE atomic model ${ }^{34}$. Electron thermal conduction is treated according to the model described by Schurtz, Nicolaï, and Busquet ${ }^{35}$. For testing purposes only, this was replaced by a Spitzer-Härm model ${ }^{36}$, leading to differences of the order of $10 \%$ in the heating dynamics.

The simulations presented here concern only the setup of the experiment at Gekko XII, as the corresponding measurements give better insight into the heating dynamics. The targets, defined in Table I and for which measurements are given in Figs. 8, 9, and 10, were simulated during 2 ns using the nominal Gekko XII parameters.

\section{A. Heat front velocity comparisons}

Fig. 11 illustrates the simulated temperature distribution in three different targets. The velocity of the heat front qualitatively appears to decrease with increasing foam density, matching the trend of the experimental data in Fig. 9. However, the simulated velocity is much higher than measured: for instance, simulations of the target B suggest that the heat front already traversed most of the $2 \mathrm{~mm}$ target at $0.6 \mathrm{~ns}$, which is significantly faster than the measured $1.4 \mathrm{~mm} / \mathrm{ns}$. To have quantitative comparison with the data, the x-ray emission predicted by the simulations was integrated along the viewing axis of the streak camera, and analyzed in the same way as the experimental data. This analysis is provided in Table II. For most targets, the simulated velocity is about twice the measured, with the densest targets giving a slightly

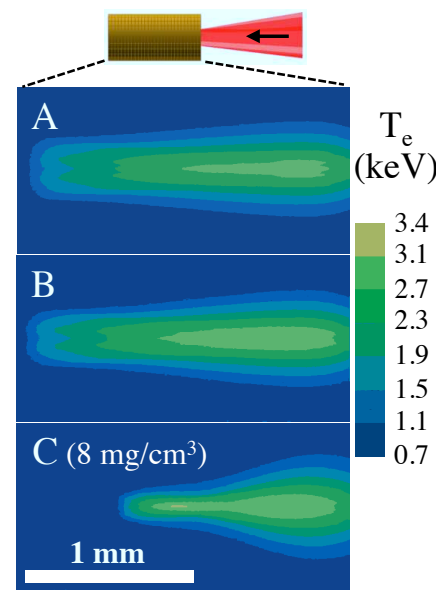

Figure 11. (Color online) Simulated temperature spatial distribution from three different targets at the laser peak intensity (0.6 ns). Only the initial target volume is represented. The laser is incoming from the right.

\begin{tabular}{|c|c|c|c|}
\hline \multirow[t]{2}{*}{ Target type } & \multirow{2}{*}{$\begin{array}{c}\text { Measured } \\
(\mathrm{mm} / \mathrm{ns})\end{array}$} & \multicolumn{2}{|c|}{ Simulated $(\mathrm{mm} / \mathrm{ns})$} \\
\hline & & $\begin{array}{c}\text { nominal } \\
\text { density }\end{array}$ & $\begin{array}{c}+4 \mathrm{mg} / \mathrm{cm}^{3} \\
\text { of water }\end{array}$ \\
\hline $\bar{A}$ & $2 \pm 0.3$ & 3.5 & 2.1 \\
\hline B & $1.4 \pm 0.2$ & 3.5 & 1.6 \\
\hline $\mathrm{C}\left(5 \mathrm{mg} / \mathrm{cm}^{3}\right)$ & - & 2.7 & 1.3 \\
\hline $\mathrm{C}\left(8 \mathrm{mg} / \mathrm{cm}^{3}\right)$ & $1.0 \pm 0.1$ & 1.8 & 0.9 \\
\hline $\mathrm{C}\left(18 \mathrm{mg} / \mathrm{cm}^{3}\right)$ & $0.5 \pm 0.1$ & 0.7 & 0.6 \\
\hline
\end{tabular}

Table II. Heat front velocity as experimentally measured and inferred from simulations. The last column corresponds to simulations where $4 \mathrm{mg} / \mathrm{cm}^{3}$ of water was artificially added to the foam.

better agreement. A similar discrepancy was observed recently by Primout et al. ${ }^{12}$ in similar conditions, using different simulation codes.

One hypothesis for this discrepancy is water that could have been adsorbed by the foams between their fabrication and their use in experiments. In an attempt to determine the amount of additional water required to match the measurements, a series of simulations have been carried out with an additional amount of water. The last column in Table II shows that $4 \mathrm{mg} / \mathrm{cm}^{3}$ of water reproduces well the experimental front velocities.

The amount of water, determined independently (see Section II), cannot account for more than a $10 \%$ change of the foam density. As a consequence, this rules out the hypothesis of adsorbed water for explaining the discrepancies of the heat front velocity.

Another hypothesis is that the foam structure, which differs from a homogeneous medium, can alter the propagation of the laser and of the ionization wave. One interpretation consists in considering a one-dimensional foam as a series of solid walls evenly separated by vacuum. The laser interacts only with a few walls (contained in one skin depth of the laser), and, once these walls have expanded 
enough so that their density has become lower than the critical density, the laser can pass through and interact with the following ones. This was studied theoretically by Gus'kov et al. ${ }^{37}$, who estimated the ionization front velocity as a function of the foam parameters and provided some comparison to experiments. This was followed by additional experimental investigations ${ }^{38}$. This approach makes use of a parameter $\alpha$ which characterizes the pores, whether they are open $(\alpha=1 / 2$, void regions are fully connected), closed ( $\alpha=1$, void regions are separated by a wall), or of any intermediate geometry. In our case, the foams A and B consist mainly of filaments attached to each other, forming a three-dimensional mesh. Thus, it corresponds to open pores. Knowing approximately the internal surface area $\left(\sim 1000 \mathrm{~m}^{2} / \mathrm{g}\right)$, we characterized $\alpha$ to be between 0.55 and 0.7 in these conditions. Using formula (27) of Ref. 37, and multiplying by the number of pores in one laser skin depth as suggested in the same reference, we match the experimental velocities for targets $\mathrm{A}$ and $\mathrm{B}$ by choosing $\alpha=0.65$ and 0.62 , respectively. However, the velocity depends very strongly on $\alpha$, so that these predictions typically vary by a factor of 2. Results from type-C targets can also be reproduced with this model assuming $\alpha>0.9$ as the nanotubular structure presents mostly closed pores. The uncertainty on $\alpha$ also induces a factor- 2 uncertainty on the predicted velocities. As a consequence, this model shows that the foam nanostructure potentially has a strong effect on the heat front velocity, but our foam characterization is insufficient to validate it quantitatively.

\section{B. Temperature comparisons}

The simulated temperature mostly agrees with the experimental data. In section IV A, we have shown that the temperature distribution, as extracted from the Ly$\alpha / \mathrm{He}-\alpha$ line ratio, exhibited a strong variation between targets $\mathrm{A}, \mathrm{B}$, and $\mathrm{C}$. This variation is observed in the LASNEX simulations, but only for targets B and C.

For a quantitative comparison, the temperature distributions were extracted from the simulations and transferred to the atomic code SCRAM for calculation of the x-ray spectra. More precisely, the distributions were weighted by the electron density $n_{e}$ and the Ti ion density $n_{T i}$ because the x-ray yield scales as $n_{e} n_{T i}{ }^{5}$. The ratio of the $\mathrm{x}$-ray yield contained in the $\mathrm{Ly}-\alpha$ and $\mathrm{He}-\alpha$ lines is given from both experimental and simulated spectra in Table III. The simulations reproduce accurately the evolution of this ratio with increasing foam density (targets $\mathrm{B}$ and $\mathrm{C}$ ), but do not accurately predict the ratio for the lowest density, lowest concentration target (type A). This latter discrepancy might be due to a poor photon statistics in the spectral measurements from target A.

Note also that these temperature comparisons are not affected by possible water contamination as this appears to have little effect on the x-ray spectra, according to the

\begin{tabular}{c|ccc} 
Target type & Measured & \multicolumn{2}{c}{ Simulated } \\
\cline { 2 - 4 } & & $\begin{array}{c}\text { nominal } \\
\text { density }\end{array}$ & $\begin{array}{c}+4 \mathrm{mg} / \mathrm{cm}^{3} \\
\text { of water }\end{array}$ \\
\hline \hline $\mathrm{A}$ & $<0.01$ & 0.04 & 0.04 \\
$\mathrm{~B}$ & $0.03 \pm 0.01$ & 0.04 & 0.04 \\
$\mathrm{C}\left(5 \mathrm{mg} / \mathrm{cm}^{3}\right)$ & $0.06 \pm 0.01$ & 0.06 & 0.05 \\
$\mathrm{C}\left(8 \mathrm{mg} / \mathrm{cm}^{3}\right)$ & $0.09 \pm 0.01$ & 0.09 & 0.09 \\
$\mathrm{C}\left(18 \mathrm{mg} / \mathrm{cm}^{3}\right)$ & $0.11 \pm 0.01$ & 0.12 & 0.11
\end{tabular}

Table III. Ratio between the Ly- $\alpha$ and He- $\alpha$ x-ray lines, as experimentally measured and inferred from simulations. This ratio relates to the electron temperature.

simulations.

\section{CONCLUSIONS}

Two new techniques for fabrication of low-density, highTi-concentration foams have been developed and tested: using ALD deposition of $\mathrm{TiO}_{2}$ on nano-structured scaffolds, up to 33 atomic $\%$ of $\mathrm{Ti}$ was obtained in a foam of density as low as $5 \mathrm{mg} / \mathrm{cm}^{3}$. This high concentration of Ti atoms implies high x-ray yields when irradiated by energetic lasers.

An experiment on the Omega laser has shown that foams with a Ti concentration of 20 at. \% converted more than $5 \%$ of the laser energy into K-shell x-rays. This is, to the authors' knowledge, the highest yield obtained with foams to date. In an experiment on the Gekko XII laser, no absolute data were available, but relative measurements indicated that foams with a $\mathrm{Ti}$ concentration of 33 at. \% yielded twice the x-ray flux. Thus, such foams could achieve the $\sim 10 \% \mathrm{CE}$ of gas $^{5}$ or metal-lined-cavity targets $^{29}$.

The experiment at Gekko XII also provided measurements of the heating dynamics in a simple geometry. The velocity of the heat front was found constant (to less than $10 \%$ ) during laser irradiation, and scaled strongly with the foam density. X-ray spectra provided insight into the variation of the peak electron temperature in the targets which was also found to scale with foam (or Ti atom) density.

These data can be used to benchmark hydrodynamics simulations in order to predict and design future targets. The code LASNEX was found to predict accurately the average electron temperatures, but the simulated heat front velocities are twice those observed in the experimental data.

We ruled out the possibility that water adsorbed in the foams could explain this discrepancy: an additional $4 \mathrm{mg} / \mathrm{cm}^{3}$ of water would have been required to match the data, and this contradicts the measured concentration of $\mathrm{H}$ atoms in the foams. The hypothesis that the foam structure could alter the laser propagation differently from a uniform medium has been shown to be plausible, but no quantitative conclusion could be drawn due 
to the limited foam nanostructure characterization and the limited precision of the currently available models. Other hypotheses, such as the effect of changing the thermal conduction model, are still under investigation.

\section{ACKNOWLEDGMENTS}

We thank Chuck Sorce, Jim Emig, Swanee Shin, and the crews from the Omega and Gekko XII facilities for their support. This work was performed under the auspices of the U.S. Department of Energy by Lawrence Livermore National Laboratory under contract DE-AC52$07 N A 27344$.

\section{REFERENCES}

${ }^{1}$ R. Tommasini, S. P. Hatchett, D. S. Hey, C. Iglesias, N. Izumi, J. A. Koch, O. L. Landen, A. J. MacKinnon, C. Sorce, J. A. Delettrez, V. Y. Glebov, T. C. Sangster, and C. Stoeckl, Phys. Plasmas 18, 056309 (2011).

${ }^{2}$ J. A. Koch, O. L. Landen, B. J. Kozioziemski, N. Izumi, E. L. Dewald, J. D. Salmonson, and B. A. Hammel, J. Appl. Phys. 105, 113112 (2009).

${ }^{3}$ D. K. Bradley, D. G. Braun, S. G. Glendinning, M. J. Edwards, J. L. Milovich, C. M. Sorce, G. W. Collins, S. W. Haan, R. H. Page, R. J. Wallace, and J. L. Kaae, Phys. Plasmas 14, 056313 (2007).

${ }^{4}$ J. Workman and G. A. Kyrala, Rev. Sci. Instrum. 72, 678 (2001).

${ }^{5}$ C. A. Back, J. Grun, C. Decker, L. J. Suter, J. Davis, O. L. Landen, R. Wallace, W. W. Hsing, J. M. Laming, U. Feldman, M. C. Miller, and C. Wuest, Phys. Rev. Lett. 87, 275003 (2001).

${ }^{6}$ K. B. Fournier, M. J. May, J. D. Colvin, J. O. Kane, M. Schneider, E. Dewald, C. A. Thomas, S. Compton, R. E. Marrs, J. Moody, E. Bond, P. Michel, J. H. Fisher, C. D. Newlander, and J. F. Davis, Phys. Plasmas 17, 082701 (2010).

${ }^{7}$ K. B. Fournier, C. Constantin, J. Poco, M. C. Miller, C. A. Back, L. J. Suter, J. Satcher, J. Davis, and J. Grun, Phys. Rev. Lett. 92, 165005 (2004).

${ }^{8}$ K. B. Fournier, J. H. Satcher, M. J. May, J. F. Poco, C. M. Sorce, J. D. Colvin, S. B. Hansen, S. A. MacLaren, S. J. Moon, J. F. Davis, F. Girard, B. Villette, M. Primout, D. Babonneau, C. A. Coverdale, and D. E. Beutler, Phys. Plasmas 16, 052703 (2009).

${ }^{9}$ F. Pérez, J. J. Kay, J. R. Patterson, J. Kane, B. Villette, F. Girard, C. Reverdin, M. May, J. Emig, C. Sorce, J. Colvin, S. Gammon, J. Jaquez, J. H. Satcher, and K. B. Fournier, Phys. Plasmas 19, 083101 (2012).

${ }^{10}$ D. Babonneau, M. Primout, F. Girard, J. P. Jadaud, M. Naudy, B. Villette, S. Depierreux, C. Blancard, G. Faussurier, K. B. Fournier, L. Suter, R. Kauffman, S. Glenzer, M. C. Miller, J. Grün, and J. Davis, Phys. Plasmas 15, 092702 (2008).

${ }^{11}$ M. Tanabe, H. Nishimura, S. Fujioka, K. Nagai, N. Yamamoto, Z. Gu, C. Pan, F. Girard, M. Primout, B. Villette, D. Brebion, K. B. Fournier, A. Fujishima, and K. Mima, Appl. Phys. Lett. 93, 051505 (2008).

${ }^{12}$ M. Primout, D. Babonneau, L. Jacquet, B. Villette, F. Girard, D. Brebion, P. Stemmler, K. Fournier, R. Marrs, M. May,
R. Heeter, R. Wallace, H. Nishimura, S. Fujioka, M. Tanabe, and H. Nagai, High Energy Density Phys. 9, 750 (2013).

${ }^{13}$ T. Boehly, Opt. Commun. 133, 495 (1997).

${ }^{14}$ C. Yamanaka, Y. Kato, Y. Izawa, K. Yoshida, T. Yamanaka, T. Sasaki, M. Nakatsuka, T. Mochizuki, J. Kuroda, and S. Nakai, IEEE J. Quantum Electron. 17, 1639 (1981).

${ }^{15}$ C. Constantin, C. A. Back, K. B. Fournier, G. Gregori, O. L. Landen, S. H. Glenzer, E. L. Dewald, and M. C. Miller, Phys. Plasmas 12, 063104 (2005).

${ }^{16}$ M. Tanabe, H. Nishimura, N. Ohnishi, K. B. Fournier, S. Fujioka, A. Iwamae, S. B. Hansen, K. Nagai, F. Girard, M. Primout, B. Villette, D. Brebion, and K. Mima, High Energy Density Phys. 6, 89 (2010).

${ }^{17}$ T. Tillotson and L. Hrubesh, J. Non-Cryst. Solids 145, 44 (1992).

${ }^{18}$ T. M. Tillotson, L. W. Hrubesh, and I. M. Thomas, Mater. Res. Soc. Proc. 121, 685 (1988).

19 J. Gross, P. R. Coronado, and L. W. Hrubesh, J. Non-Cryst. Solids 225, 282 (1998).

${ }^{20}$ J. Aarik, A. Aidla, H. Mändar, and T. Uustare, Appl. Surf. Sci. 172, 148 (2001).

${ }^{21}$ A. Hodge, J. Biener, J. Hayes, P. Bythrow, C. Volkert, and A. Hamza, Acta Mater. 55, 1343 (2007).

${ }^{22}$ M. M. Biener, J. Biener, A. Wichmann, A. Wittstock, T. F. Baumann, M. Bäumer, and A. V. Hamza, Nano Lett. 11, 3085 (2011).

${ }^{23}$ CRC Handbook of Metal Etchants (CRC Press, 1990) p. 598.

${ }^{24}$ J. Tirira, Y. Serruys, and P. Trocellier, Forward Recoil Spectrometry (Plenum Press, New York, 1996).

${ }^{25}$ L. R. Doolittle, Nucl. Instrum. Meth. B 9, 344 (1985).

${ }^{26}$ J. Baglin, A. Kellock, M. Crockett, and A. Shih, Nucl. Instrum. Meth. B 64, 469 (1992).

${ }^{27}$ National Laser User Facility User's Guide, University of Rochester, Laboratory for Laser Energetics, Rochester, NY (2007).

${ }^{28}$ H. N. Kornblum, R. L. Kauffman, and J. A. Smith, Rev. Sci. Instrum. 57, 2179 (1986).

${ }^{29}$ F. Girard, M. Primout, B. Villette, P. Stemmler, L. Jacquet, D. Babonneau, and K. B. Fournier, Phys. Plasmas 16, 052704 (2009); Phys. Plasmas 18, 079901 (2011).

${ }^{30}$ D. K. Bradley, P. M. Bell, J. D. Kilkenny, R. Hanks, O. Landen, P. A. Jaanimagi, P. W. McKenty, and C. P. Verdon, Rev. Sci. Instrum. 63, 4813 (1992).

${ }^{31}$ C. A. Back, J. Davis, J. Grun, L. J. Suter, O. L. Landen, W. W. Hsing, and M. C. Miller, Phys. Plasmas 10, 2047 (2003).

${ }^{32}$ S. Hansen, J. Bauche, C. Bauche-Arnoult, and M. Gu, High Energy Density Phys. 3, 109 (2007).

${ }^{33}$ J. A. Harte, W. E. Alley, D. S. Bailey, J. L. Eddleman, and G. B. Zimmerman, ICF Quarterly Report, July-September 1996, Volume 6, Number 4, Lawrence Livermore National Laboratory, document no. UCRL-LR-105821-96-4.

${ }^{34}$ H. Scott and S. Hansen, High Energy Density Phys. 6, 39 (2010).

${ }^{35}$ G. P. Schurtz, P. D. Nicolaï, and M. Busquet, Phys. Plasmas 7, 4238 (2000).

${ }^{36}$ L. Spitzer and R. Härm, Phys. Rev. 89, 977 (1953).

${ }^{37}$ S. Y. Gus'kov, J. Limpouch, P. Nicolaï, and V. T. Tikhonchuk, Phys. Plasmas 18, 103114 (2011).

${ }^{38}$ P. Nicolaï, M. Olazabal-Loumé, S. Fujioka, A. Sunahara, N. Borisenko, S. Gus'kov, A. Orekov, M. Grech, G. Riazuelo, C. Labaune, J. Velechowski, and V. Tikhonchuk, Phys. Plasmas 19, 113105 (2012). 